\title{
Increased Levels of Circulating Islet Amyloid Polypeptide in Patients with Chronic Renal Failure Have No Effect on Insulin Secretion
}

\author{
Bernhard Ludvik, * Martin Clodi, * Alexandra Kautzky-Willer, ${ }^{*}$ Markus Schuller, ${ }^{\ddagger}$ Helmut Graf, * Engelbert Hartter, ${ }^{\star}$ \\ Giovanni Pacini, ${ }^{\mathbf{s}}$ and Rudolf Prager* \\ * Department of Medicine III, Division of Endocrinology and Metabolism, ${ }^{\ddagger}$ Department of Medicine IV, University of Vienna, \\ 1090 Vienna, Austria; ${ }^{\S}$ Consiglio Nazionale delle Ricerche Institute of System Dynamics and Bioengineering, (LADSEB CNR), \\ 35020 Padua, Italy
}

\begin{abstract}
To elucidate the metabolism of islet amyloid polypeptide (IAPP) with respect to a possible renal elimination we investigated IAPP levels in 20 lean, nondiabetic patients with renal failure maintained on chronic hemodialysis (HD) and in 20 healthy controls. The basal levels of IAPP were significantly higher in uremic patients than in controls $(15.1 \pm 3.2$ vs. 3.2 $\pm 0.2 \mathrm{pM}, P<0.001$ ) suggesting renal excretion of IAPP. To investigate the impact of chronically elevated levels of endogenous IAPP on insulin secretion and insulin sensitivity, a frequently sampled intravenous glucose tolerance test (FSIGT) was performed in a subset of patients on hemodialysis and in age-matched healthy controls $(\mathrm{C})$ and obese patients with normal (NGT) and with impaired glucose tolerance (IGT). Insulin sensitivity index (SI) was $8.7 \pm 1.5$ in $\mathrm{C}(P<0.05$ vs. NGT, $P<0.01$ vs. IGT $), 5.4 \pm 0.9$ in HD $(P<0.05$ vs. IGT $), 3.1 \pm 1.0$ in NGT, and $2.0 \pm 0.5$ in IGT. First phase insulin secretion was increased in patients on HD compared with those of several control groups. The results of this study therefore indicate a renal route of metabolism of IAPP. Increased endogenous circulating IAPP levels over a long period of time do not lead to a decrease in insulin release in patients on HD and do not cause the insulin resistance commonly seen in obesity and diabetes. Increased levels of circulating IAPP therefore are not likely to be a pathogenetic factor in the development of non-insulin-dependent diabetes mellitus (NIDDM). (J. Clin. Invest. 1994. 94:2045-2050.) Key words: amylin • oral glucose tolerance test • intravenous glucose tolerance test $\bullet$ insulin sensitivity $\bullet$ non-insulin-dependent diabetes mellitus

\section{Introduction}

Islet amyloid polypeptide (IAPP) ${ }^{1}$ or amylin has recently been identified as the major protein component of amyloid deposits

Address correspondence to Rudolf Prager, MD, Department of Medicine III, Div. of Endocrinology and Metabolism, University of Vienna, Wahringergurtel 18-20, 1090 Vienna, Austria.

Received for publication 18 March 1994 and in revised form 29 June 1994.

1. Abbreviations used in this paper: BMI, body mass index; FSIGT, frequently sampled intravenous glucose tolerance test; HD, hemodialysis; IAPP, islet amyloid polypeptide; IGT, impaired glucose tolerance; irm, immune reactive material; NGT, normal glucose tolerance; NIDDM, non-insulin-dependent diabetes mellitus.

J. Clin. Invest.

(C) The American Society for Clinical Investigation, Inc.

0021-9738/94/11/2045/06 \$2.00

Volume 94, November 1994, 2045-2050 of pancreatic islets of type II diabetic patients $(1,2)$. IAPP is a 37-amino acid peptide with a sequence homology to calcitonin gene-related peptide and is stored together with insulin in the B cell secretory granules of the human pancreatic islets (3). In in vitro experiments, IAPP inhibits insulin-stimulated glycogen synthesis in rat skeletal muscle (4) and impairs glucose utilization (5). It has further been reported, that high doses of IAPP inhibit glucose-stimulated insulin release from isolated rat islets (6). However, other investigators have not supported a role for IAPP in the regulation of insulin secretion $(7,8)$. In animal experiments, high-dose infusion of IAPP causes insulin resistance $(9,10)$. These insulin antagonist actions of IAPP led to speculations about a possible role of IAPP in the pathogenesis of non-insulin-dependent diabetes mellitus (NIDDM) (11).

In man, it has been shown, that IAPP is co-secreted with insulin from the pancreatic $B$ cell $(12,13)$ and that levels of IAPP are elevated in obesity (14) and after dexamethasone treatment (15). In NIDDM, a decrease of stimulated IAPP release precedes impairment of insulin secretion $(14,16)$. The increase of IAPP in obese and dexamethasone treated subjects parallels that of insulin and is therefore likely to be secondary to the insulin resistance seen in these patients. To investigate the primary effect of IAPP on insulin secretion and insulin sensitivity, Bretherton-Watt and co-workers infused IAPP in lean, nondiabetic subjects (17). Circulating IAPP levels $>90$ times normal postprandial peaks were necessary to decrease glucose-stimulated insulin secretion, but had no effect on glucose disposal. The authors concluded that circulating IAPP is unlikely to play a role in the pathogenesis of NIDDM, but a long-term effect of increased IAPP levels could not be ruled out. To investigate the effect of circulating IAPP on insulin secretion and insulin resistance in man, however, a suitable model would be a condition, in which IAPP levels are chronically elevated, outside the context of insulin resistance.

The metabolism and excretion of IAPP have not yet been elucidated. Considering a possible renal elimination of IAPP we investigated IAPP, insulin, and C peptide levels in fasting state and after hemodialysis in lean, nondiabetic patients with renal failure. If IAPP levels were increased in these patients, renal failure may serve as a model of chronic increase of endogenous IAPP in lean, nondiabetic subjects. Measurement of insulin sensitivity and secretion in these patients would allow an estimate of the impact of increased circulating IAPP levels on the development of NIDDM.

\section{Methods}

\section{Subjects}

The study group consisted of 20 lean, nondiabetic patients with renal failure maintained on hemodialysis (mean age $39.8 \pm 6 \mathrm{yr}$, body mass 
index [BMI] $\left.21.2 \pm 1.2 \mathrm{~kg} / \mathrm{m}^{2}\right) ; 20$ lean, nondiabetic control subjects (mean age $42.6 \pm 14.7 \mathrm{yr}$, BMI $22.0 \pm 0.7 \mathrm{~kg} / \mathrm{m}^{2}$ ); 16 obese patients (mean age $40 \pm 4 \mathrm{yr}, \mathrm{BMI} 39 \pm 1.3 \mathrm{~kg} / \mathrm{m}^{2}$ ), 8 with normal and 8 with impaired glucose tolerance according to classification of the National Diabetes Data Group (18). All subjects gave informed consent to participate in this study, and had no personal or family history of diabetes mellitus. The protocol of the study was approved by the Ethical Committee of the University of Vienna.

\section{Protocol}

Study I. After an overnight fast blood was drawn in 20 control subjects and in 20 patients with renal failure before and immediately after hemodialysis for measurement of glucose, insulin, C-peptide, and IAPP.

Study II. Eight patients on hemodialysis (HD), 8 age- and weightmatched lean control subjects and 16 age-matched obese subjects underwent an oral glucose tolerance test $(75 \mathrm{~g})$ to measure glucose, insulin, and IAPP secretion. On a separate day, insulin secretion capacity and insulin sensitivity was assessed by a frequently sampled intravenous glucose tolerance test (FSIGT).

\section{Oral glucose tolerance test (OGTT)}

The subjects underwent a standard ( $75 \mathrm{~g}$ ) OGTT after an overnight fast. Blood was drawn at $0,30,60,90,120$, and $180 \mathrm{~min}$ for measurement of glucose, $\mathrm{C}$ peptide, insulin, and IAPP.

\section{Frequently sampled intravenous glucose tolerance test (FSIGT)}

For each subject, the experimental protocol started at 8:00 AM, after an overnight fast. A catheter was inserted into an antecubital vein for blood sampling and into a contralateral antecubital vein for glucose injection. Basal samples were drawn at $-20,-10$, and -1 min. At time 0 , glucose $(300 \mathrm{mg} / \mathrm{kg}$ body wt) was injected in $1 \mathrm{~min}$. Additional samples were collected at $2,3,4,5,6,8,10,12,13,16,19,22,25$, $30,40,50,60,70,80,90,100,110,120,140,160,180,210$, and 240 min for measurement of glucose and insulin.

\section{Assays}

Blood glucose was determined by an American Monitor-Parallel Analyzer. Serum insulin and $C$ peptide were measured by commercial RIA (RIA-gnostR Insulin; Behringwerke AG, Marburg, Germany; RIAmatR C-peptid II; Byk-Sangtek, Dietzenbach, Germany). IAPP was measured by an RIA developed in our laboratory (13). To determine IAPP, venous blood samples (at least $10 \mathrm{ml}$ ) are collected into icechilled, EDTA-coated polystyrene tubes. EDTA plasma is obtained by centrifugation, and IAPP is extracted from the plasma by 'Sep-Pak C18' cartridges (Waters/Millipore, Milford, MA) with methanol/trifluoroacetic acid/water as the mobile phase (p.A. grade; Merck, Darmstadt, Germany). The cartridges are activated with $5 \mathrm{ml}$ of methanol followed by $5 \mathrm{ml}$ of methanol/TFA/water in the volume ratio of 5:0.5:94.5. IAPP is then adsorbed by slow passage of the plasma samples (at least $5 \mathrm{ml}$ each) over the cartridges (vacuum manifold). After a washing step with $4 \mathrm{ml}$ of methanol/TFA/water 20:0.5:79.5 by volume, the peptide is desorbed by $2 \times 2 \mathrm{ml}$ of methanol/TFA/water 90:0.5:9.5 by volume. The eluates are dried by a vacuum-concentrator (SVC $220 \mathrm{H}$, Savant Instruments, Farmingdale, NY) and stored at $-20^{\circ} \mathrm{C}$ until IAPPRIA (for up to $2 \mathrm{wk}$ ). Extraction of IAPP prevents from cross-reaction and assay interference by uremic products normally cleared by the kidneys.

For IAPP-RIA the dry plasma extracts are reconstituted in $350 \mu \mathrm{l}$ of phosphate RIA-buffer (0.05 mol Na-phosphate, $\mathrm{pH} 7.4,0.95 \mathrm{~g} \mathrm{Na}$ azide, $1 \mathrm{mmol}$ EDTA, $3 \mathrm{~g}$ bovine serum albumin, $1 \mathrm{ml}$ Triton X-100 per liter) and triplicate $100-\mu \mathrm{l}$ aliquots are incubated with $100 \mu \mathrm{l}$ of rabbit anti-human IAPP (Peninsula, Belmont, CA), simultaneously to $100-\mu \mathrm{l}$ aliquots of appropriate dilutions of IAPP calibrator (range 4$260 \mathrm{fmol} / \mathrm{ml})$ at $+4^{\circ} \mathrm{C}$ for $24 \mathrm{~h} 100 \mu \mathrm{l}$ of 125I-IAPP-tracer $(\sim 20.000$ cpm; Peninsula, Belmont, CA) are then added for another $24 \mathrm{~h}$. Peptide bound to antibody finally is separated from unbound by precipitation with $0.5 \mathrm{ml}$ antibody-immunoprecipitating reagent (sheep anti-rabbit, Sorin/Biomedica, Salluggia, Italy) for $30 \mathrm{~min}$ at room temperature, followed by addition of $1 \mathrm{ml}$ of ice-chilled RIA buffer and collection of the precipitate by centrifugation at $+4^{\circ} \mathrm{C}(5,000 \mathrm{~g}, 30 \mathrm{~min})$. Supernates are removed by suction and the radioactivity of the pellets is determined by gamma counting. IAPP content of the samples is calculated by computer-aided processing of results from gamma counting, using a logit-log-transformation of the calibrator curve.

We use dilutions of anti-IAPP providing antibody binding of tracer at zero dose of IAPP (B0) ranging from 15 to $20 \%$ of the total. Nonspecific binding of tracer is $<3 \%$ of total, the lowest detectable dose of IAPP clearly different from zero is $0.4 \mathrm{fmol} /$ tube, i.e., $0.3 \mathrm{pM}$, if $5 \mathrm{ml}$ of plasma are used (criterion: B0 - $3 \mathrm{SD}$ ). Calibrator doses equivalent to 80,50 , and $20 \%$ of tracer-binding relative to zero dose are $2.2,6.2$, and $18 \mathrm{fmol}$, respectively. Within and between run precision within this linear range of the RIA are 10 and $15 \%$.

To test the recovery of IAPP from plasma, three EDTA-plasma samples with low ( $<1 \mathrm{pm}$; patients with type I diabetes), as well as four samples with high $(>10 \mathrm{pM})$ endogenous IAPP content were spiked by addition of 1,2 , and $4 \mathrm{pM}$ of synthetic IAPP. Recoveries ranged from $75 \%$ as the lowest and $90 \%$ as the highest extreme $(85 \pm 5 \%)$. IAPP values paralleled the calibrator curve, when aliquots of $5 \mathrm{ml}$ of plasma samples $(n=5)$ with endogenous IAPP content ranging from 6 to $15 \mathrm{pM}$ were diluted with $0.15 \mathrm{M} \mathrm{NaCl}$ to ratios of plasma $/ \mathrm{NaCl}$ of $1: 0.5,1: 1,1: 2$, and 1:3.

\section{Characterization of plasma-IAAP by sequential HPLC of plasma extracts and RIA}

The IAAP immunoreactive material (IAPP-irm) measured by RIA in plasma extracts is not necessarily identical to authentic, intact IAAP. To test for a possible heterogenity of plasma IAAP-irm we performed HPLC of plasma extracts, followed by determination of IAAP-irm in the eluate from the column.

Pooled plasma extracts were obtained as described above for the RIA procedure from $50 \mathrm{ml}$ each of EDTA plasma from four healthy subjects, and four patients on hemodialysis. For HPLC the extracts were reconstituted in a solution containing $0.3 \mathrm{~g}$ of bovine serum albumine in $100 \mathrm{ml}$ of water. HPLC instrumentation was: the gradient pump SP 8800 from Spectra-Physics (San Jose, CA), the UV/VIS-detector model Chrom-A-Scope No. 1970 from BarSpec (Rehovot, Israel), and the fraction collector Mo. 203 from Gilson Medical Elec. Inc. (Middleton, WI). Aliquots of reconstituted plasma extract corresponding to 5 and $10 \mathrm{ml}$ of plasma were injected onto a reversed phase column (solid phase material Nucleosil 100-3C18; Machery/Nagel, Düren, Germany; column dimensions $150 / 4 \mathrm{~mm}$, column filled by Forschungszentrum, Seibersdorf, Austria). The mobile phase consisted of a linear gradient of 10:100 ml-60:100 ml of acetonitrile in water, containing 1:100 ml of trifluoroacetic acid (TFA), and was delivered at a flow rate of $1 \mathrm{ml} /$ $\mathrm{min}$ for $40 \mathrm{~min}$. 1-ml fractions of the eluate were collected and brought to dryness by vacuum concentration. After reconstitution of the dry eluates in RIA buffer, their content of IAAP-irm was determined by RIA as described above.

\section{Data analysis}

FSIGT date were submitted to the computer program, which calculates the characteristic metabolic parameters by fitting glucose and insulin data to the minimal model that describes the time courses of glucose and insulin concentrations (MINMOD; 19). The glucose disappearance minimal model accounts for the effect of insulin on glucose disappearance after exogenous glucose injection. It provides the insulin sensitivity index SI $\left[\mathrm{min}^{-1} /(\mathrm{U} / \mathrm{ml})\right]$.

\section{Statistical analysis}

All data are presented as means \pm SEM. Analysis of variance was used to compare insulin secretion (SI), plasma IAPP, glucose, insulin, and $\mathrm{C}$ peptide concentrations among the groups. Statistical analysis for the 


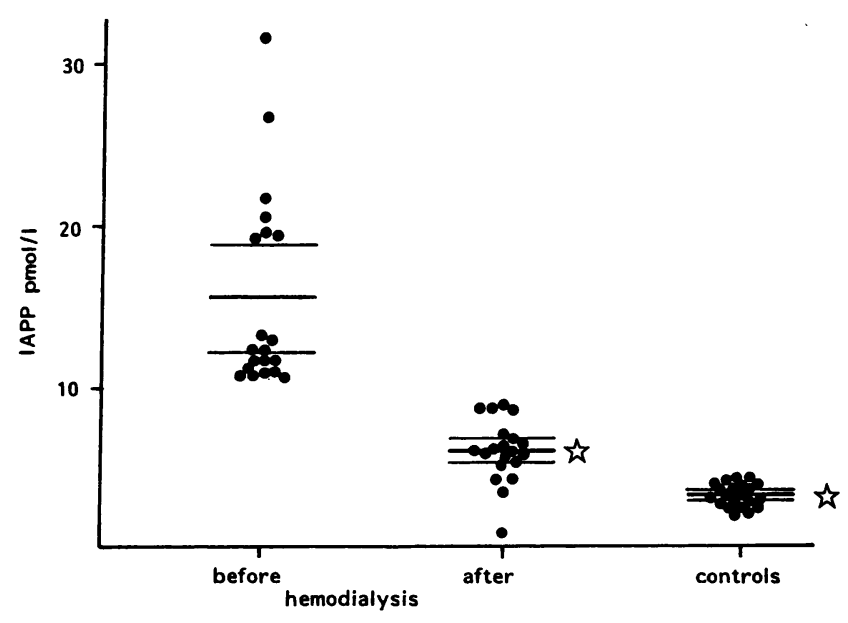

Figure 1. Basal IAPP levels in patients on HD before and after hemodialysis and in healthy controls, ${ }^{*} P<0.001$ (before HD vs. $C$, before vs. after HD).

increase of peptides from basal was done with the student's $t$ test. A $P$ value $<0.05$ was considered significant.

\section{Results}

\section{Basal data}

The basal levels of IAPP (Fig. 1) were significantly higher in uremic patients than in controls $(15.1 \pm 3.2$ vs. $3.2 \pm 0.2 \mathrm{pM}, P$ $<0.001)$. After HD, IAPP decreased significantly from $15.1 \pm 3.2$ to $5.8 \pm 0.6 \mathrm{pM}(P<0.001)$. Insulin levels were significantly higher in patients than in controls $(107.4 \pm 12.0 \mathrm{vs.}$ $45.1 \pm 10.2 \mathrm{pM}, P<0.05)$ and did not decrease significantly during HD $(69.6 \pm 12.1 \mathrm{pM})$. C peptide was significantly increased in patients compared to controls $(7.7 \pm 0.4$ vs. $0.6 \pm 0.1$ $\mathrm{nM}, P<0.001)$ and decreased significantly after HD to $5.1 \pm 0.6$ $\mathrm{nM}(P<0.001)$.

\section{Stimulated data}

OGTT. During the OGTT glucose levels (Fig. $2 a$ ) were significantly higher in patients on HD compared with controls at $120 \mathrm{~min}(8.1 \pm 1.0$ vs. $4.9 \pm 0.9 \mathrm{mM}, P<0.05)$ and at $180 \mathrm{~min}$ ( $6.7 \pm 0.6$ vs. $4.4 \pm 0.5 \mathrm{mM}, P<0.05$ ). Basal Insulin levels (Fig. $2 b)$ were significantly higher in patients on $\mathrm{HD}(96.1 \pm 15.2 \mathrm{vs}$. $45.3 \pm 10.2 \mathrm{pM}$ in controls, $P<0.05)$ and increased significantly to a peak value of $471.5 \pm 117.2$ vs. $250.2 \pm 49.8 \mathrm{pM}$ (in controls) after $60 \mathrm{~min}$. At $180 \mathrm{~min}$, insulin remained significantly higher in patients on HD compared with controls (391.8 \pm 198.2 vs. $101.4 \pm 39.6 \mathrm{pM}, P<0.05)$. C peptide levels increased from $5.1 \pm 1.1$ vs. $0.7 \pm 0.1 \mathrm{nM}(P<0.001)$ to a peak of $8.5 \pm 0.4$ vs. $3.5 \pm 0.2 \mathrm{ng} / \mathrm{ml}$ after $60 \mathrm{~min}(P<0.001)$. C peptide gradually declined in controls, however, in patients on $\mathrm{HD}$ it remained significantly elevated $(8.3 \pm 0.2$ vs. $1.9 \pm 0.5 \mathrm{ng} / \mathrm{ml}$ after 180 min, $P<0.001$ ). In controls, IAPP levels (Fig. $2 c$ ) increased significantly from $3.2 \pm 1.6 \mathrm{pM}$ to a peak level of $8.2 \pm 1.0 \mathrm{pM}$ after $60 \mathrm{~min}(P<0.05)$, then declining to $4.8 \pm 1.1 \mathrm{pM}$ after $180 \mathrm{~min}$. In patients on HD IAPP (basal 17.2 $\pm 3.7 \mathrm{pM}$ ) could be stimulated in each patient, however, the SEM of IAPP in the patients group of renal failure was so large that the increment of IAPP calculated for all patients did not reach statistical significance.
Integrated insulin response during OGTT (areas under the curve) was $36096 \pm 5430 \mathrm{pM} / 3 \mathrm{~h}$ in controls and $64620 \pm 7512$ $\mathrm{pM} / 3 \mathrm{~h}$ in patients on HD and showed no statistically significant difference.

Characterization of plasma-IAAP by sequential HPLC. The results of this experiment are shown in Fig. 3, confirming that the IAPP-irm measured by RIA in plasma extracts is identical to authentic, intact IAAP.

IVGTT. Fig. 4 shows the increase of insulin after intravenous glucose. Insulin increased from basal $85 \pm 7 \mathrm{pM}$ in HD, $47 \pm 3 \mathrm{pM}$ in $\mathrm{C}, 69 \pm 6 \mathrm{pM}$ in normal glucose tolerance (NGT), and $120 \pm 11 \mathrm{pM}$ in impaired glucose tolerance (IGT) to a peak of $306 \pm 18 \mathrm{pM}$ (at $3 \mathrm{~min}$ ) for controls (C), 806 $\pm 100 \mathrm{pM}$ (at $3 \mathrm{~min}$ ) for $\mathrm{HD}, 264 \pm 42 \mathrm{pM}$ (at $10 \mathrm{~min}$ ) for NGT, and at $330 \pm 24 \mathrm{pM}$ (at $60 \mathrm{~min}$ ) for IGT. SI and total insulin secretion are shown in Table I. In short, SI was insignificantly lower in HD compared to C $(P=0.07)$, and significantly lower in NGT vs. $\mathrm{C}$ and in IGT vs. $\mathrm{C}$ and HD. Total insulin secretion was significantly higher in NGT and HD compared with C. In IGT insulin secretion was highest among all groups, the comparisons, however, did not reach statistical significance because of the large range of SEM.

\section{Discussion}

This study demonstrates substantially increased levels of circulating IAPP in lean, nondiabetic patients on hemodialysis. This finding not only suggests an important role of the kidneys in the excretion of IAPP but also presents a model to study the impact of chronically elevated IAPP levels on glucose metabolism in lean subjects. The results of the metabolic studies demonstrate that none of these patients has become diabetic despite long standing increased circulating IAPP and that elevated IAPP levels do not impair insulin secretion or lead to the insulin resistance commonly seen in obesity or diabetes.

Very little is known about the metabolism of IAPP. Sowa et al. (10) found a reduced effect of IAPP on insulin-stimulated glucose metabolism when it was infused via the portal vein compared with a peripheral vein suggesting an important role of the liver in the degradation of IAPP. This finding could not be confirmed by a recent study by Sanke et al. (16), which reports no hepatic effect of infused amylin in rats. Although we cannot exclude a hepatic extraction of IAPP, the almost fourfold increase of circulating levels of IAPP, presumably on the basis of decreased renal clearance, in the patients studied is comparable with that of $C$ peptide, and therefore strongly suggests predominant renal excretion of IAPP analogous to excretion of $\mathrm{C}$ peptide. A possible assay interference by products normally cleared by the kidneys could be ruled out by the HPLC experiment. The evidence for renal elimination of IAPP is further substantiated by our very recent finding, that IAPP kinetics during an OGTT resemble those of $C$ peptide rather than those of insulin (20).

The role of circulating IAPP in the pathogenesis of NIDDM remains controversial. IAPP has been shown to impair glucose disposal in in vitro experiments $(4,5)$ and in animal studies $(9,10)$. While a decrease of insulin secretion from the isolated pancreas after IAPP perfusion has been reported (6), other authors could not confirm these findings $(7,8)$. Since these studies, however, used extremely high doses of IAPP, the relevance of their findings to the physiologic role of IAPP in human 

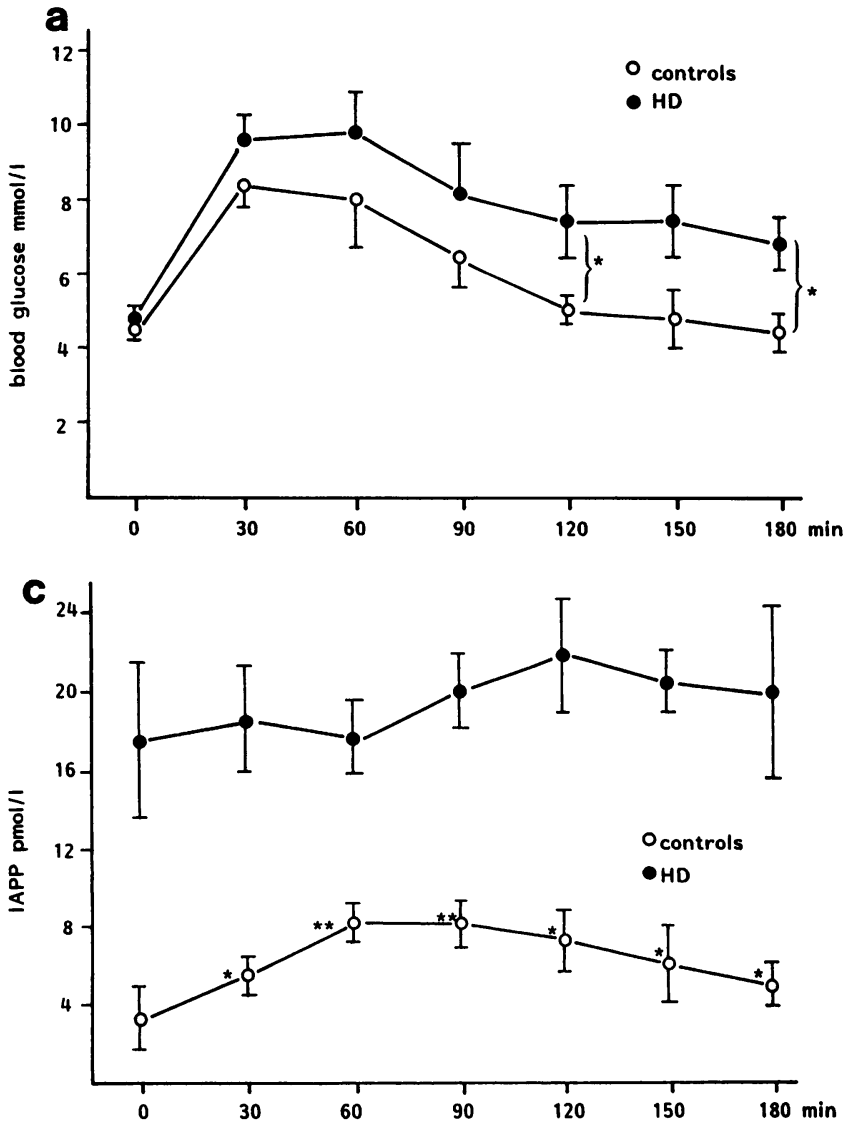

subjects might be questioned. In humans, circulating IAPP is increased together with insulin in obese patients with normal and impaired glucose tolerance (14) and in patients treated with dexamethasone (15). It is therefore assumed, that this increase in both hormones is secondary to insulin resistance and thus it is not possible to infer a causal role for IAPP in the pathogenesis of insulin resistance. To study the effect of IAPP on glucose metabolism, Bretherton-Watt and co-workers studied insulin secretion and insulin sensitivity during high-dose infusion of IAPP

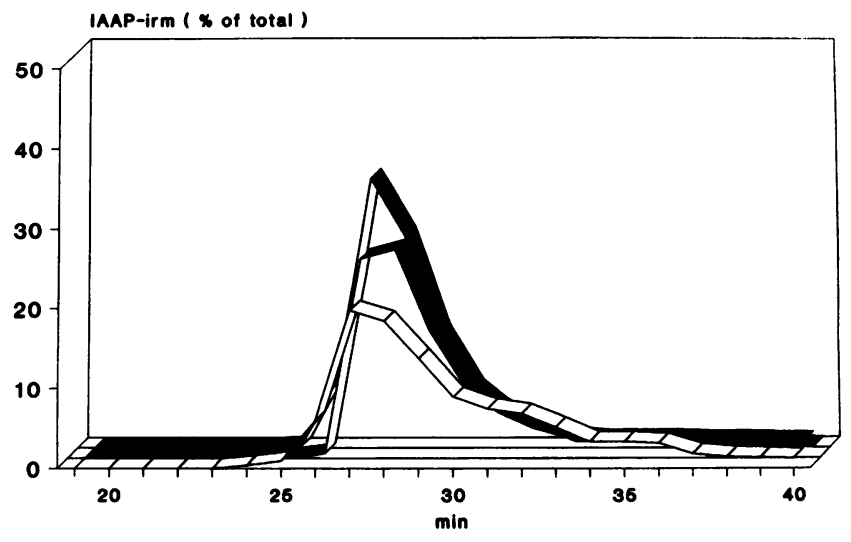

Figure 3. IAAP-irm in HPLC fractions originating from the pooled plasma extracts from healthy persons (open), patients on hemodialysis treatment (black), compared with IAAP-irm of authentic synthetic IAAP ( shaded) subjected to HPLC.

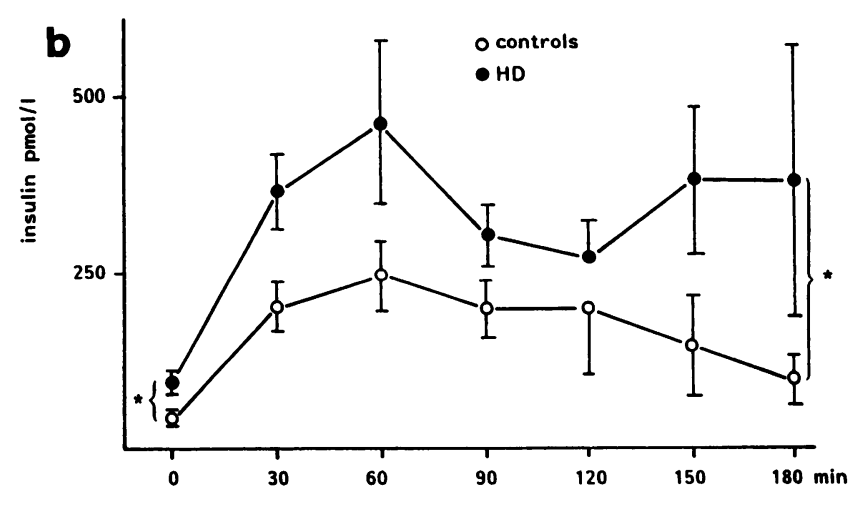

Figure 2. Stimulated levels of glucose $(a)$, insulin $(b)$, and IAPP $(c)$ in patients on HD and in healthy controls, ${ }^{*} P<0.05,{ }^{\ddagger} P<0.001$ ( $a$ and $b)$ : HD vs. C, (c) from basal.

in lean, non-diabetic subjects (17). IAPP concentrations $>90$ times normal postprandial peaks were necessary to decrease glucose-stimulated insulin secretion, but had no effect on glucose disposal. The authors concluded that IAPP is unlikely to act as a circulating hormone. This study, however, could only assess the acute effects of IAPP on glucose metabolism and,

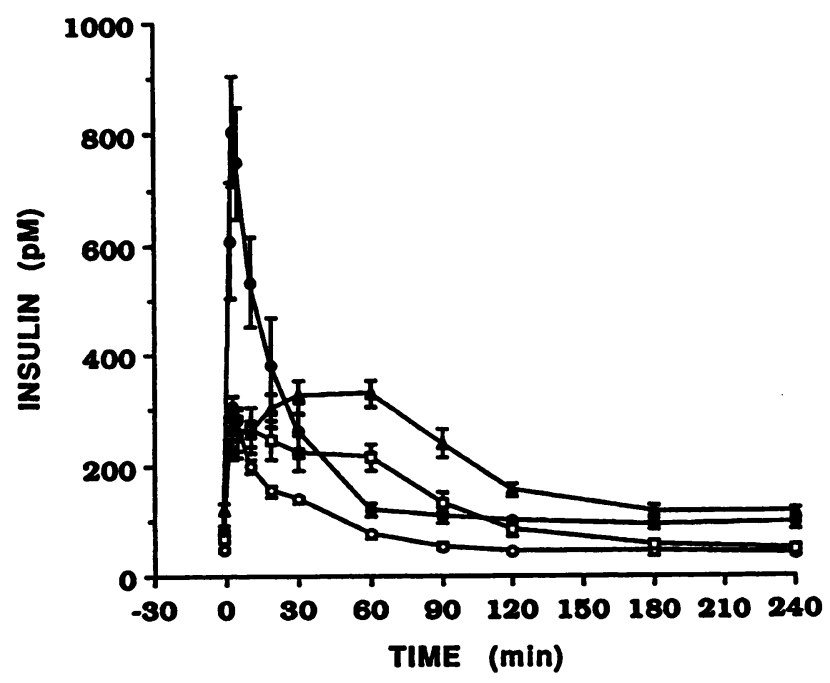

Figure 4. Insulin levels following intravenous glucose in controls, patients on HD, obese patients with NGT and IGT. (-O-, controls;

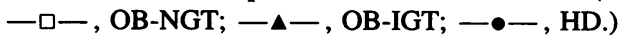


Table I. SI and Insulin Secretion in Controls, Patients on HD, and Obese Subjects with NGT and IGT

\begin{tabular}{lcc}
\hline & SI & Total secretion \\
\hline & $\min ^{-1} /(\mu U / m l)$ & $p M$ in 240 min \\
HD & $5.4 \pm 0.9$ & $5299 \pm 477^{1}$ \\
C & $8.7 \pm 1.5$ & $3017 \pm 354$ \\
Obese NGT & $3.1 \pm 1.0^{*}$ & $4588 \pm 596^{*}$ \\
Obese IGT & $2.0 \pm 0.5^{\ddagger \S}$ & $10703 \pm 3686$ \\
\hline
\end{tabular}

${ }^{*} P<0.05$ NGT vs. $C ;{ }^{\ddagger} P<0.001$ IGT vs. $C ;{ }^{8} P<0.01$ IGT vs. HD; $' P<0.01$ HD vs. $C$.

therefore, does not exclude a possible role of chronically increased IAPP levels. Another objection is the biological activity of the IAPP infused in this study. As only $\mathrm{COOH}$-terminal amidated IAPP, which is presumed to be the biologically active moiety (21), was infused, a potential role of the nonamidated form could not be elucidated and the biological activity of synthesized amidated or nonamidated peptide cannot be guaranteed in the absence of known responsive tissues for assessing the viability of preparations.

Renal failure serves as a model of chronic elevation of circulating endogenous IAPP in nonobese, nondiabetic patients and therefore reflects the long-term effect of IAPP on glucose homeostasis. We therefore investigated the influence of increased IAPP levels on insulin sensitivity and insulin secretion, as a decrease in both is a hallmark of NIDDM. It is well known that chronic renal failure is associated with glucose intolerance and insulin resistance (22). In our patients the oral glucose tolerance test showed significantly higher glucose levels at 120 and $180 \mathrm{~min}$, and a higher, although not significant, integrated insulin response in patients on $\mathrm{HD}$, which reflects the lower, though not statistically significant insulin sensitivity compared with controls. These findings of a modest decrease of insulin sensitivity are in good agreement with the report that insulin resistance, which is a feature of untreated renal failure, improves or even reverses after initiation of hemodialysis (23). In patients on HD, SI was slightly higher than in obese patients with normal glucose tolerance and significantly higher than in patients with impaired glucose tolerance. The patients on HD exhibited basal IAPP levels of about $17 \mathrm{pM}$, whereas those for obese patients have been shown to be in the range of 4-5 pM (14). Substantially increased IAPP levels therefore do not cause the degree of insulin resistance commonly found in obese (24) and NIDDM patients (25). Furthermore, the apparent disparity between the degree of insulin resistance and the basal IAPP levels makes it very unlikely that IAPP is involved in the pathogenesis of insulin resistance.

To study the impact of increased IAPP on insulin secretion an FSIGT was performed in a subset of study subjects. If increased IAPP is likely to adversely affect insulin secretion, at least a blunted insulin response following intravenous glucose should be expected. In patients on HD, however, we found an exaggerated first phase insulin response compared to control and obese subjects. This phenomenon has been described by several authors $(23,26-28)$. While the exact cause remains to be clarified, the increased first phase insulin response could be attributed to the prevailing PTH level. In accordance with published results (27), the second phase insulin secretion was slightly higher than in normal subjects, but lower than in obese subjects, reflecting the different insulin sensitivity in the respective groups. This finding clearly demonstrates that chronic fourfold elevation of IAPP levels compared with controls does not impair insulin secretion.

Although impaired glucose tolerance and insulin resistance can be seen in patients on HD (23), there is no report on an increased onset of NIDDM in uremic patients. This is in agreement with the observation that none of our patients has become diabetic despite a longstanding elevation of IAPP. Very recently, Fox and co-workers (29) presented a human islet amyloid polypeptide transgenic mouse model and investigated glucose metabolism and amyloid deposition. Despite a fivefold increase of circulating IAPP, insulin, and glucose levels were not elevated compared with control animals and the investigators were unable to detect amyloid deposits. These findings support our results in human subjects.

In conclusion, the results of this study demonstrate that circulating IAPP is elevated in patients on hemodialysis which emphasizes an important role of the kidneys in excreting IAPP. The chronically increased levels of endogenous IAPP in these patients do not lead to the insulin resistance usually seen in obesity and NIDDM or an impairment of insulin secretion, both of which are hallmarks of NIDDM. Our findings, therefore, do not support a role of circulating IAPP in the pathogenesis of NIDDM. This is further substantiated by the fact that even a marked, longstanding elevation of circulating IAPP did not lead to the development of NIDDM in these patients. The impact of IAPP on the pathogenesis of type 2 diabetes via paracrine precipitation in the pancreatic islets cannot be excluded.

\section{Acknowledgments}

We thank R. Kargl, Dr. M. Brunnbauer, and Dr. M. Capek for their expert technical assistance.

\section{References}

1. Westermark, P., C. Wernstedt, E. Wilander, and K. Sletten. 1986. A novel peptide in the calcitonin gene related peptide family as an amyloid fibril protein in the endocrine pancreas. Biochem. Biophys. Res. Commun. 140:826-831.

2. Cooper, G. J. S., A. Willis, A. Clark, R. C. Turner, R. B. Sim, and K. B. M. Reid. 1987. Purification and characterization of amyloid-rich pancreases of type 2 diabetic patients. Proc. Natl. Acad. Sci. USA. 84:8628-8632.

3. Lukinius, A., E. Wilander, G. T. Westermark, U. Engström, and P. Westermark. 1989. Co-localization of islet amyloid polypeptide and insulin in the B cell secretory granules of the human pancreatic islets. Diabetologia. 32:240-244.

4. Cooper, G. J., B. Leighton, G. D. Dimitriades, M. Parry-Billings, J. M Kowalchuk, K. Howland, J. B. Rothbard, A. D. Willis, and K. B. M. Reid. 1988. Amylin found in amylin deposits in human type 2 diabetes mellitus may be a hormone that regulates glycogen metabolism in skeletal muscle. Proc. Natl. Acad. Sci. USA. 85:7763-7766.

5. Leighton, B., J. S. Garth, and G. J. S. Cooper. 1988. Pancreatic amylin and calcitonin gene related peptide (CGRP) cause resistance to insulin in skeletal muscle in vitro. Nature (Lond.). 335:632-635

6. Ohsawa, H., A. Kanatsuka, T. Yamaguchi, H. Makino, and S. Yoshida. 1989. Islet amyloid polypeptide inhibits glucose-stimulated insulin secretion from isolated rat pancreatic islets. Biochem. Biophys. Res. Commun. 160:961-967.

7. O'Brien, T. D., P. Westermark, and K. H. Johnson. 1990. Islet amyloid polypeptide (IAPP) does not inhibit glucose-stimulated insulin secretion from isolated perfused rat pancreas. Biochem. Biophys. Res. Commun. 170:1223-1228.

8. Nagamatsu, S., R. J. Caroll, G. M. Grodsky, and D. F. Steiner. 1990. Lack of islet amyloid polypeptide regulation of insulin secretion in normal rat islets. Diabetes. 39:871-874.

9. Molina, J. M., G. J. S. Cooper, B. Leighton, and J. M. Olefsky. 1990. 
Induction of insulin resistance in vivo by amylin and calcitonin gene-related peptide. Diabetes. 39:260-265.

10. Sowa, R., T. Sanke, J. Hirayama, H. Tabata, H. Furuta, S. Nishimura, and K. Nanjo. 1990. Islet amyloid polypeptide amide causes peripheral insulin resistance in vivo in dogs. Diabetologia. 33:118-120.

11. Clark, A., G. J. S. Cooper, C. E. Lewis, J. F. Morris, A. C. Willis, K. B. M. Reid, and A. C. Turner. 1987. Islet amyloids formed from diabetesassociated peptide may be pathogenetic in type-2 diabetes. Lancet. 231-234.

12. Kahn, S., D. A. D'Alessio, M. W. Schwartz, W. Y. Fujimoto, J. W. Ensinck, G. J. Taborsky, and D. Porte. 1990. Evidence of cosecretion of isle amyloid polypeptide and insulin by B cells. Diabetes. 39:634-638.

13. Hartter, E., T. Svoboda, B. Ludvik, M. Schuller, B. Lell, E. Kuenburg M. Brunnbauer, W. Woloszczuk, and R. Prager. 1991. Basal and stimulated plasma levels of pancreatic amylin indicate its co-secretion with insulin in humans Diabetologia. 34:52-54.

14. Ludvik, B., B. Lell, E. Hartter, C. Schnack, and R. Prager. 1991. Decrease of stimulated amylin release precedes impairment of insulin secretion in type 2 diabetes. Diabetes. 40:1615-1619.

15. Ludvik, B., M. Clodi, A. Kautzky-Willer, M. Capek, E. Hartter, G. Pacini, and R. Prager. 1993. Effect of dexamethasone on insulin sensitivity, islet amyloid polypeptide and insulin secretion in humans. Diabetologia. 36:84-87.

16. Sanke, T., T. Hanabusa, Y. Nakano, C. Oki, M. Okai, S. Nishimura, M Kondo, and K. Nanjo. 1991. Plasma islet amyloid polypeptide (amylin) levels and their responses to oral glucose in type 2 (non-insulin-dependent) diabetic patients. Diabetologia. 34:129-132.

17. Bretherton-Watt, D., S. G. Gilbey, M. A. Ghatei, J. Beacham, A. D. Macrae, and S. R. Bloom. 1992. Very high concentrations of islet amyloid polypeptide are necessary to alter the insulin response to intravenous glucose in man J. Clin. Endocrinol. Metab. 74:1032-1035.

18. National Diabetes Data Group. 1979. Classification and diagnosis of diabetes mellitus and other categories of glucose intolerance. Diabetes. 28:1039-1957.

19. Pacini, G., and R. N. Bergmann. 1986. MINMOD: A computer program to calculate insulin sensitivity and pancreatic responsivity from the frequently sampled intravenous glucose tolerance test. Comput. Methods Programs Biomed. 23:113-122.

20. Kautzky-Willer, A., K. Thomaseth, G. Pacini, M. Clodi, B. Ludvik, C. Streli, W. Waldhäusl, and R. Prager. 1994. Role of islet amyloid polypeptide secretion in insulin resistant-humans. Diabetologia. 37:188-194.

21. Mosselman, S., J. W. M. Hoppener, J. Zandberg, A. D. M. van Mansfield, A. H. M. Geurts van Kessel, C. J. M. Lips, and H. S. Janz. 1988. Islet amyloid polypeptide: identification and chromosomal localisation of the human gene. FEBS (Fed. Eur. Biochem. Soc.) Lett. 239:227-232.

22. DeFronzo, R. A., A. Alvestrand, and D. J. Smith. 1984. Insulin, glucose, amino acid and lipid metabolism in chronic renal insufficiency. In Nephrology,

Vol II., Proceedings of the ninth international congress of nephrology. Robinson R. R., editor. Springer-Verlag, New York Inc., New York. 1334-1348.

23. DeFronzo, R. A., A. Alvestrand, D. Smith, and R. Hendler. 1981. Insulin resistance in uremia. J. Clin. Invest. 67:563-568.

24. Prager, R., P. Wallace, and J. M. Olefsky. 1986. In vivo kinetics of insulin action on peripheral glucose disposal and hepatic glucose output in normal and obese subjects. J. Clin. Invest. 78:472-481.

25. Olefsky, J. M., O. G. Kolterman, and J. A. Scarlett. 1982. Insulin action and resistance in obesity and non-insulin-dependent type II diabetes mellitus. Am. J. Physiol. 243E:15.

26. Akmal, M., S. G. Massry, D. A. Goldstein, P. Fanti, A. Weisz, and R. A. DeFronzo. 1985. Role of parathyroid hormone in the glucose tolerance of chronic renal failure. J. Clin. Invest. 75:1037-1044.

27. O. Schmitz. 1989. Effects of physiologic and supraphysiologic hyperglycemia on early and late-phase insulin secretion in chronically dialyzed uremic patients. Acta Endocrinol. 121:251-258.

28. Graf, H., R. Prager, J. Kovarik, A. Luger, G. Schernthaner, and W. F. Pinggera. 1985. Glucose metabolism and insulin sensitivity in patients on chronic hemodialysis. Metabolism. 34:974-977.

29. Fox, N., J. Schrementi, M. Nishi, S. Ohagi, S. J. Chan, J. A. Heisserman, G. T. Westermark, A. Leckström, P. Westermark, and D. F. Steiner. 1993. Human islet amyloid polypeptide transgenic mice as a model of non-insulin-dependent diabetes mellitus (NIDDM). FEBS (Fed. Eur. Biochem. Soc.) Lett. 323:40-44. 